\title{
Behavioural Descriptions of Indian Pangolins (Manis crassicaudata) in Captivity
}

\author{
Rajesh Kumar Mohapatra ${ }^{1}$ and Sudarsan Panda ${ }^{2}$ \\ ${ }^{1}$ Pangolin Conservation Breeding Center, Nandankanan Zoological Park, Odisha 754005, India \\ ${ }^{2}$ Nandankanan Zoological Park, Odisha 754005, India \\ Correspondence should be addressed to Rajesh Kumar Mohapatra; rajesh.wildlife@gmail.com
}

Received 25 August 2014; Accepted 27 October 2014; Published 19 November 2014

Academic Editor: Greg Demas

Copyright ( 2014 R. K. Mohapatra and S. Panda. This is an open access article distributed under the Creative Commons Attribution License, which permits unrestricted use, distribution, and reproduction in any medium, provided the original work is properly cited.

\begin{abstract}
Conservation breeding programmes as an essential tool for conservation of endangered species require a sound knowledge on behaviour of the species. At present time, knowledge of behaviour and biology of Indian pangolins is inadequate and inconsistent. During the present study, an ethogram was developed based on the behavioural observations of seven Indian pangolins (Manis crassicaudata) at Pangolin Conservation Breeding Centre, Nandankanan Zoological Park, Odisha, India, between February 2012 and January 2013. A total of 27 behaviours of seven distinct behavioural categories (stationary body positions, locomotory patterns, maintenance behaviours, explorative behaviours, defensive behaviours, reproductive/social behaviours, and others) were described and illustrated. The results offer a consistent frame of reference for further studies on behavioural patterns of Indian pangolins. Besides, these preliminary observations could be useful in management and breeding of the species in captivity.
\end{abstract}

\section{Introduction}

Indian pangolin (Manis crassicaudata; family Manidae; order Pholidota) is one of the eight living species of pangolins of the world. They are toothless mammals with 11-13 rows of large overlapping horny scales, long protrusible tongue, and prehensile tail with a terminal scale on its ventral side $[1$, 2]. They are solitary, fossorial, nocturnal, and insectivorous. Indian pangolin occurs throughout peninsular India $[3,4]$. Its range extends as far west as Pakistan, east to West Bengal (India) and Yunnan (Southwest China), south to Sri Lanka, and north to Nepal [5]. Their populations are increasingly under threat throughout their range due to domestic and international demand for live pangolins and their skin, scales, and meat. The biology of Indian pangolins particularly low reproductive rate and a wide distribution make them vulnerable to overexploitation [6]. Captive breeding programme, which is essential for the conservation of the species requires detailed knowledge about the behaviour of the species.

The Indian pangolin is a poorly known species. Little effort has been devoted to understanding its biology, ecology, and behaviour, perhaps due to nocturnal and secretive habit of the species. Available published information on Indian pangolin is primarily from natural history observations, rescue reports, reports of illegal trade, and captive studies. Many practical questions remain unanswered because of incomplete information on ecological and behavioural biology of the species. Comprehensive knowledge of pangolin behaviour will be central to assess welfare and management of pangolins for potential captive breeding programme [7]. The ethogram for Indian pangolin could not be found in the available literature. Keeping all the points in view, an attempt was made to prepare a standard ethogram for Indian pangolins in the present paper based on the observation in captivity at Pangolin Conservation Breeding Center (PCBC), Nandankanan Zoological Park, Odisha, India.

\section{Methodology}

Nandankanan Zoological Park has the experience of maintaining Indian pangolins since 1962 [8]. A Pangolin Conservation Breeding Center (PCBC) was established in 2008 
in the park with an objective of scientific management and breeding of Indian pangolins. Study was conducted on seven (4F:3M) Indian pangolins between February 2012 and January 2013. Details of housing and husbandry for these animals were described elsewhere $[9,10]$. Briefly, pangolins were housed in naturalistic soil-substrate enclosures of $4.8 \mathrm{~m}$ $\times 4.2 \mathrm{~m} \times 3.0 \mathrm{~m}$ dimensions, with hollow wooden logs, dry tree branches, and saucer shaped pool as enrichment materials. The daily husbandry routine consisted of enclosure cleaning, water replacement, feeding, and health monitoring.

Since pangolins are nocturnal and intermittently active, their behaviours were recorded through digital video recording system assisted by infrared enabled CCTV cameras, following Mohapatra and Panda [9]. Most of the observations were based on the individually housed adult pangolins except one female pangolin (mother) with its young (observation period $=91$ nights) and pair housing of opposite sex adult individuals (observation period $=14$ nights). Besides CCTV monitoring, pangolins were also observed intermittently through direct observation using low intensity light followed by photodocumentation of different behaviours. While developing ethogram, behaviours were defined in terms of consequences, that is, effect of the behaviour of the pangolin on its environment and on other individuals or vice versa. Behaviours sharing similar function were clustered into appropriate behavioural categories. The behavioural repertoire presented in this paper is purely qualitative and the descriptions cover most common behavioural state and events shown by Indian pangolins.

\section{Results}

A total of 27 different behaviour patterns were observed. All the behaviour patterns observed were grouped into one of the seven different behavioural categories. These categories were stationary body positions, locomotory patterns, maintenance behaviours, explorative behaviours, defensive behaviours, reproductive/social behaviours, and others. The observed behaviours with their respective behavioural categories were briefly described. In addition, some of these behaviours were illustrated in Figure 1.

3.1. Stationary Body Positions. This behavioural category includes stationary posture with either open or closed eyes while the pangolins were sleeping or resting.

3.1.1. Sleeping. During sleeping, the pangolins remain in a prolonged motionless state with minimal or no limb or head movement. They usually attain a coiled posture with closed eyes (Figure 1(a)). They move deep inside the burrow to rest/sleep during the daytime in soil-substrate enclosures. When such provisions were not available (e.g., enclosures with concrete substrate), pangolins prefer corner area for sleeping. If hollow wooden logs were provided, they move inside the log during the daytime.
3.1.2. Resting. During resting the pangolins were found immobile with eyes open or partially closed. Three distinct resting postures were recorded:

(1) being recumbent with little or no weight born on limbs and ventral surface of the body resting on the ground and claws of forelimb bent backward (Figure 1(b)),

(2) coiled body posture with lateral recumbence and head between the limbs (Figure 1(a)),

(3) laying on back exposing ventral surface of their body (Figure 1(c)).

3.2. Locomotion Pattern. Observed locomotion patterns of pangolins include quadrupedal movement from one point to another, horizontally or vertically, towards or away from facing direction. There were two kinds of locomotory behaviours.

3.2.1. Climbing. While standing, both forelimbs and hind limbs were lifted sequentially from time to time, moving upward, downward, or sideward (Figure 1(d)). They climb up in the facing direction and climb down either in the facing or backward direction. They are agile climbers and, in wild conditions, they probably climb trees in pursuit of ants [11]. They use their claws of the limbs to grip the tree and their prehensile tail for support while positioning their forelimbs further up the tree trunk [4].

3.2.2. Walking. Manis crassicaudata walks quadrupedally, with back arched and tail held off from the ground (Figure 1(e)). During walking, the front toes were bent under soles. The whole sole of hind limb is however applied to the ground [4]. Pangolin can change its direction on the ground or while moving in the branches by making a turn, instead of backward movement. In some instances, for example, during digging, pangolin moves backward as it throws dug-out soil outside the burrow. Besides, backward movement was also sometimes observed, when pangolin climbs down from the branches and chain-linked fence.

3.3. Maintenance Behaviours. Maintenance behaviour is performed by an animal in the normal course of its daily activities and is critical to its survival [12]. Six types of maintenance behaviours exhibited by the pangolins were described below.

3.3.1. Drinking. Drinking takes place by lowering head below the level of back and consuming water by lapping movement of the tongue (Figure 1(f)). Although pangolins drink water as and when required, they may live without water for a longer period [4].

3.3.2. Feeding. Feeding involves lowering of head below the level of back and ingestion of feed (ants and termites) by frequent in and out movement of its glutinous tongue (Figure 1(g)). Feeding comprises selection and consumption 


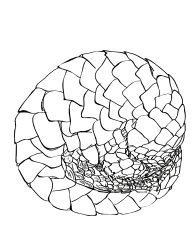

(a)

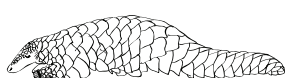

(b)

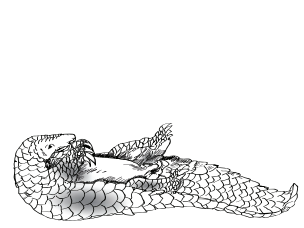

(c)

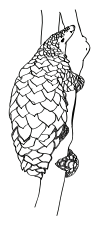

(d)

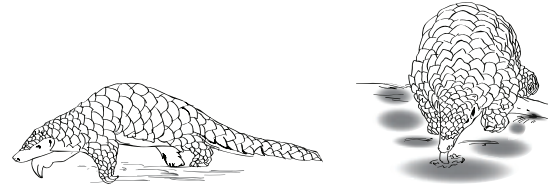

(e) (f)

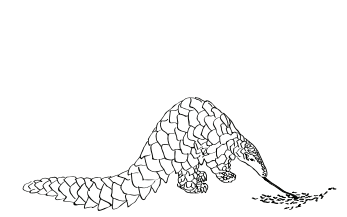

(g)

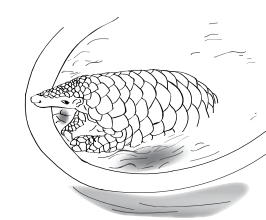

(h)

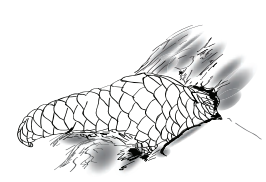

(i)

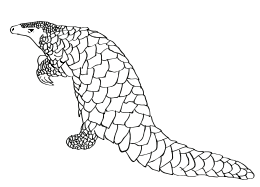

(j)

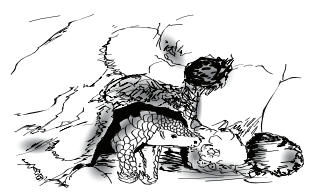

(k)

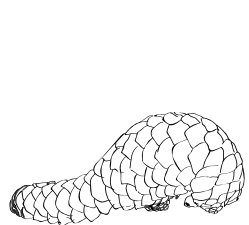

(1)

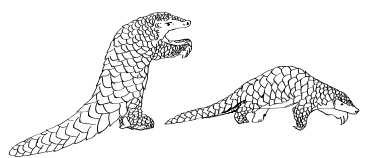

(m)

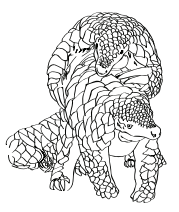

(n)

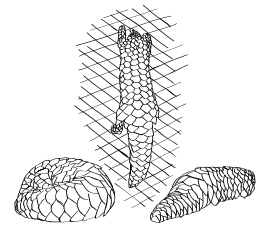

(p)

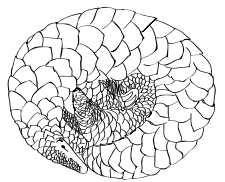

(q)

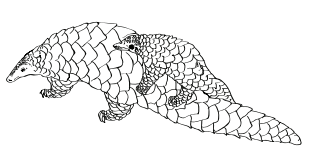

(r)

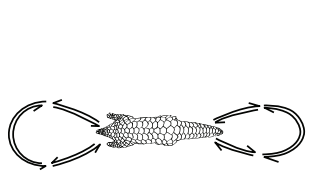

$(\mathrm{s})$

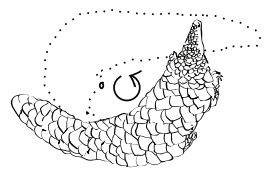

(t)

FiguRE 1: (a) Resting in coiled posture, (b) resting in a straight posture, (c) laying on back, (d) climbing, (e) walking, (f) drinking, (g) feeding, (h) bathing, (i) digging, (j) bipedal stand, (k) secretive look, (l) head bend towards ventral surface in defence, (m) bipedal chase, (n) mounting, (o) copulation, ( $\mathrm{p}$ ) retreat, (q) baby pangolin suckling, (r) baby pangolin on her mother's back, ( $\mathrm{s}$ ) pacing in " 8 " shape, and ( $\mathrm{t}$ ) pacing in "O" shape.

of available food resources. In the wild, the food of pangolins consists of egg, young and adult of termites and ants. They relished ants' eggs more than the ants themselves [4]. In captivity, they prefer to eat their ant/termite diet before the intake of supplementary feed, that is, minced hard-boiled eggs and milk powder. When termite comb was provided, the pangolins break down the comb into small pieces which makes the inhabitants, that is, termites, come out or assessable to feed. Then the termites were rapidly licked off by its glutinous tongue and swallowed.

3.3.3. Bathing. Pangolin dives into water from one end of the pool and comes out from the other end. The other posture includes laying submerged inside the pool keeping the anterior portion of the body out of the water (Figure $1(\mathrm{~h})$ ). At times, pangolin plays by moving to and fro inside the pool.

3.3.4. Digging. Pangolins have specialized adaptation for fossorial life and usually live in burrows made by themselves [4]. They dig burrows with the help of their strong curved claws of the forelimbs and their hind limbs help in throwing soils out of the burrows (Figure 1(i)) [11]. Pangolins were found to exhibit less overground activities and spend more time inside the burrows during the winter months than those of summer and rainy season.
3.3.5. Defecating. It refers to elimination of faeces in a quadrupedal standing position with hind limbs placed apart and head lowered or bent towards the ventral surface of the body.

3.3.6. Territorial Marking. Pangolins usually urinate in a quadrupedal standing position; the posture is merely the same as when defecating. The urine is usually eliminated on the substrate but sometimes pangolins spray urine while climbing or clinging. The later appears to be a marking behaviour as the urine is deliberately spread along the tree trunk or on substrate. They also emit a strong musky anal secretion, which could be a territorial marking [13].

3.4. Explorative Behaviours. Observed exploratory behaviours of pangolins were directed towards their proximate environment, including enclosure furnishings and/or conspecifics. Three types of explorative behaviours observed during the present study were described below.

3.4.1. Sniffing. During quadrupedal locomotion, pangolins exhibit short head movements directed towards its proximate environment in a vertical (below to above or vice versa) or horizontal plane (left to right or vice versa) to the longitudinal axis of the body. Such behaviours may contribute 
to detecting odours in air, locating feed, locating intruder or animal keeper, locating conspecific as a part of social interaction between a mother and her young, and sexual odour discrimination between the opposite sex individuals.

3.4.2. Bipedal Stand. Pangolins rise on their hind limbs and exhibit sniffing behaviour (Figure 1(j)). The forelimbs remain folded and free. At times, pangolin exhibits supporting bipedal stand where pangolin rests its forelimb on concrete wall or on tree trunk and explores the surroundings or interacts with other pangolins at neighbouring enclosures.

3.4.3. Secretive Look. At times, pangolin came out of burrow partially, that is, anterior half of the body visible to the outside (Figure $1(\mathrm{k})$ ), and exhibits sniffing behaviour.

3.5. Defensive Behaviours. When alarmed, pangolin rolls up into a ball as a defensive posture and may produce hissing sound. These behaviours are described here below.

3.5.1. Alert. It is the attainment of a brief immobile state by the pangolin, interrupting any activity it was engaged in; head points to the direction of a noise source, if any; it usually occurs in the presence of animal keeper. At times, such behaviour may be followed by bipedal stand, sniffing, or movement of pangolin into a shelter, for example, hollow wooden log or to the burrow, away from the source of noise or animal keeper.

3.5.2. Defensive Postures. Upon hearing any threatening sound, pangolin bends its head down, positioning it between the forelimbs (Figure 1(l)). In defence, the pangolin curls itself into an armoured ball, exhibiting an enormous muscular power which defies any ordinary attempt to uncoil it [4]. When captured from tail to make them uncoil, they rotate their body in both clockwise and anticlockwise along their longitudinal axis to escape from the grip. They use their hind limbs to push out the hold. Upon sensing any intruder or threat, they move fast into the burrow or climb over tree trunks or to the chain-linked fence.

3.5.3. Vocalisation. The only sound produced by the pangolin is a loud hiss, usually under stress or excitement [4]. During the study period, loud hissing sound was exhibited by the pangolins when disturbed and during mating between opposite sex individuals. At times, hissing sound was also produced during exploration and mother-young interactions.

3.6. Reproductive and Social Behaviours. Behaviours which include interaction among two individuals except aggression were included in this behavioural category. Such behaviours include a sequence of events that occur between opposite sex adult individuals and interactions among mother pangolin and her young, where the action of one individual may evoke a behavioural response in the other. Seven such behaviours were described here below.
3.6.1. Courtship. At PCBC, pangolins were housed in such a way that a pangolin can find a chance to interact with the opposite sex individual housed in the adjacent enclosure. Though there was no direct visual contact between individual pangolins when they were on ground, occasionally they do climb up the mound, water pool, or chain-linked fence and interact with each other. Such interaction includes a bipedal stand or resting posture near the chain-linked fence and sniffing or looking at the adjacent enclosure for presence of the opposite sex individual. At times, while interacting in a climbed posture, urine may squirt out by either of the individuals. Male pangolins were also observed repetitively following the gait of a female pangolin housed in the adjacent enclosure. Considering the above behaviours as courtship behaviour, the opposite sex individuals involved in such interactions were released in a concrete floored enclosure for mating purpose under keen observation.

3.6.2. Approaching. It includes walking or climbing movement towards another individual followed by nosonasal or nosogenital sniffing. The above behaviour may lead to exhibition of one of the three possible behaviours: (i) female pangolin may remain stationary, allowing male pangolin to mount; (ii) male may chase the female pangolin as she quickly walks away; (iii) female pangolin may retreat, attaining a coiled posture, and the male walks away from her.

3.6.3. Chasing. It is quadrupedal movement exhibited by one pangolin to follow another pangolin of the opposite sex. The speed of chasing gait is greater than the normal walking gait. A long period of sniffing between individuals occurs before chasing. Occasionally while chasing, the male pangolin rose on its hind limb with forelimbs extended apart and walked bipedally few steps towards the female pangolin to mount her (Figure 1(m)).

3.6.4. Mounting. The male climbs up the female's back from rear or side with his claws of forelimb grasping female's body. The male fully extends his neck over the female's head and remains parallel to her (Figure 1(n)). The male adjusts his relative position with the female to attain an ideal copulation state. Mounting behaviour may contribute to testing the receptiveness of the female to copulate with. If the female was found receptive, mounting may lead to the next behavior, that is, copulation; otherwise the female moves out of clasp and become retreat.

3.6.5. Copulation. After obtaining an ideal posture with his neck fully extended to point at the female's head, the male grasps the female's tail with his tail and inserts his genitalia to that of female's (Figure 1(o)). Copulation may occur in lateral mounting position. Intromission may be conformed (very difficult) if semen was observed afterwards in the genitalia. Event terminated when individuals break bodily contact. Upon termination of copulation, the pair move away separately and at times become retreat. 
3.6.6. Retreat. Retreat may be observed in pangolins as a precopulatory or postcopulatory behaviour in response to the opposite sex individual. It includes coiling around itself into a ball on substrate (similar to resting postures) or clinging on chain-linked fence or on dry tree trunk (Figure 1(p)). At times, male pangolin was observed mounting the female pangolin which was still in a retreat posture and tries to uncoil her by expelling/dragging the tail aside with the help of his claws of forelimbs.

3.6.7. Mother-Young Interaction. Indian pangolins usually give birth to single young $[3,14]$, but occasionally two are born [4]. Births have been reported throughout the year except for May and June months [10]. A $10.6 \mathrm{~kg}$ female gave birth at Nandankanan Zoological Park, Odisha, to an offspring that weighed $235 \mathrm{~g}$ and measured $30 \mathrm{~cm}$ in total length including $12.5 \mathrm{~cm}$ long tail [14].

Indian pangolins have a pair of mammary glands in their thoracic region. Young pangolin suckles from her mother while positioned amid mother's coiled body (Figure 1(q)). At times, baby hides its head underneath the ventral surface of her mother keeping its tail curling up mother's body or tail. As the baby was growing, the mother pangolin used to relax its coil to accommodate the increasing size of the baby [8]. Young are carried on the dorsal base of the mother's tail $[3,15]$. Young pangolin climbs on mother holding the tail base of the mother pangolin with its limbs and its tail may remain parallel to that of the mother or move to a side (Figure 1(r)). When not riding, the young pangolin usually walks nearby her mother. The mother intermittently inspects the baby pangolin. Explorative movement with intermittent sniffing behaviour was observed in the mother pangolin, when the young pangolin moved to a distance. Repeated burrow inspection, that is, mother pangolin moves to the burrow and comes back after a short bout of staying inside the burrow, was observed when the young pangolin was present inside the burrow. When disturbed, the mother pangolin gets coiled into a sphere around the young pangolin [15].

3.7. Other Behaviours. Some behaviours not included in the above behavioural categories, for example, aggression, pacing, clinging, and signs of sickness, are described below.

3.7.1. Aggression. No direct observations were made of this particular behaviour during the present study. However, the evidence of death of a male pangolin on 25th July 2010 due to male-male aggression implied that pangolins (at least male pangolins) exhibit aggressive behaviours. One of the male pangolin was seriously injured at its neck leading to his death. The injury appears to be caused by the claws of forelimbs of the other male pangolin. The evidence suggested that besides digging the claws are also used for aggressive encounters.

3.7.2. Pacing. Pacing behaviour was observed in two pangolins during study period. It includes repetitive quadrupedal walking movements in same path without any goal. Observed pacing behaviours can be grouped into two types according to the shape of the path the pangolins usually follow while pacing: (i) pacing in "8" shape (Figure $1(\mathrm{~s})$ ) and (ii) pacing in "O" shape (Figure 1(t)). Such behaviours are considered stereotypic and may associate with stress due to suboptimal captive environment. Stereotypic behaviours are repetitive, unvarying, and apparently functionless behaviour patterns which captive animals may develop as a response to physical restraint, lack of stimulation, or inescapable fear or frustration. Independent evidence shows that they are associated with poor welfare [16].

3.7.3. Clinging. Pangolins climb the chain-linked fence and remain in a hanging posture, preferably in high places with the help of claws of their forelimbs and hind limbs and with support of their tail tip. Head curled inward ventrally and intermittent urine spray were observed at times. Pangolins also exhibit clinging behaviour over the dry tree branches installed in the enclosure. They can remain clinging for whole day. Clinging may cause injury in limbs and make the animal stressed.

3.7.4. Signs of Sickness. The primary sign of good health status of pangolin is sound feed intake as they became off feed when sick. Regular measurement weight of the individual pangolin can provide information about the overall growth and health status as the pangolins were found to lose weight when sick. Body weight of an animal is associated with many features of physiology, ecology, and life history and is also an indicator of overall physical condition [17]. Regular observation for presence of any injury and ectoparasites and for secretion from their natural orifices like nose, mouth, genitalia, and so forth can help to monitor their health status. Pangolins with nasal discharge were observed producing a sound like "umh" repetitively as a sign of respiratory distress. At times, pangolin uses the front limbs or hind limbs to scratch body parts, probably to get rid of ectoparasites (ticks) or other foreign objects on the body. A sick pangolin remains less active and spends more time in stationary posture, for example, resting or sleeping. The tail of a healthy pangolin that usually is held off from ground while walking was found dragged when the animal is sick. Sick individuals may develop an inclination to spend more time laying inside water in pool. Such behaviour may lead to decline in normal body temperature, so it causes further deteriorating of the health status of the pangolin.

\section{Discussion}

In a captive situation, an understanding of animal behaviour is essential for the maintenance of healthy and contented animals. Any project that involves the captive maintenance of animals groups should assign part of its resources for structuring its ethogram [18]. The present study addresses commonly observed behaviours of Indian pangolin and is completely descriptive rather than quantitative. Many of the behaviours performed by $M$. crassicaudata were similar to that described for other pangolin species [19-22]. Although behavioural repertoire presented here was based on preliminary observations, it can be used as a frame of reference for details for behavioural studies of Indian pangolin in 
the future. It is crucial for a sound understanding of physical, social, and psychological aspects of the animals that serves as an essential tool to meet husbandry and animal conservation goals [23].

Feeding was found to be the first behaviour exhibited by Indian pangolins once they emerge from their burrow. But, Thai et al. [22] reported defecation as an initial activity in captive Sunda pangolins ( $M$. javanica). They have also stated that most of the Sunda pangolins defecate in water and some individuals dig small holes in the ground and defecate inside these holes. During the present study, captive Indian pangolins were usually found defecating on the substrate soil, towards corner or peripheral areas of the enclosure. Defecation inside pool by two individuals was observed regularly during the summer season. Defecation inside small hole or near the opening of abandoned burrow was also occasionally observed. Pangolins have very poor sense of vision and hearing but an excellent sense of smell [3]. They often stand on their hind limbs with head elevated to survey the surroundings [3] and sniff intermittently for locating feed, intruder, and conspecifics. In the wild, pangolins dig both to reach at food resources (e.g., termites) and to build living burrows $[2,4,21]$. Wet soils were found to be a preferred site for digging by pangolins at PCBC. Besides, when they were swapped into other enclosures, they dig out their own burrow instead of using the existing burrows of the previously housed pangolin. Observed copulation posture of $M$. crassicaudata during the present study was similar to that described for Cape pangolins (M. temminckii) [24]. Social interaction between mother and young observed in Indian pangolins appears to be similar to that described for Chinese pangolins (M. pentadactyla) [21] and Cape pangolins ( $M$. temminckii) [20].

Behaviours such as bathing inside pool, resting on back exposing the ventral surface of the body outward, and increased burrow utilization during winter months were believed to be associated with thermoregulation. Bathing behaviour was observed regularly during the summer and rainy season but rarely during the winter months. Bathing was also observed as a postmating and postmounting behaviour in either of the individuals (male/female). Thai et al. [22] observed increased bathing activity in $M$. javanica after feeding on live ants, which may help them to cool down, to reduce itchiness caused by ant bite, or to remove ants from underneath scales. Jacobson et al. [25] observed a female Cape pangolin laying in shade on her back exposing her belly during a hot day, permitting the animal to cool off. Pangolins were found exhibiting less overground activities during the winter months which might be associated with thermoregulation as the recorded temperature fluctuations inside burrow (minimum to maximum temperature range $=17-24.5^{\circ} \mathrm{C}$ ) were apparently lower than that of the outside $\left(15.5-34.5^{\circ} \mathrm{C}\right)[26]$. Increase in ambient temperature beyond $33^{\circ} \mathrm{C}$ may induce heat stress whereas sharp decrease in temperature may cause pneumonia leading to death in Chinese pangolins [27]. Thai et al. [22] stated that thermoregulation may play a role in the lower mortality rate of $M$. javanica residing in the "pangolarium" compared to the quarantine facility.
Pacing was the only stereotypic behaviour observed during the present study in two pangolins at the center. Such behaviour has also been observed in $M$. javanica and $M$. pentadactyla [19]. Subsequent rearrangements of enclosure furnishing or swapping of pangolins among enclosures was found useful to alleviate such behaviour. Thai et al. [22] frequently observed some of the stressed behaviours in Sunda pangolins during quarantine period. These include rapidly climbing on the enclosure wire mesh and along the wire ceiling, running very quickly on the ground or branches, repeatedly putting their head through the wire mesh while clawing at the mesh, and scratching at the door of the enclosure. Pangolins displaying these behaviours lose weight, often injure themselves, and usually die [22]. Though such behaviours are not observed in pangolins at PCBC, pangolins were found to lose weight when sick and few days before death.

\section{Conclusion}

The present study describing 27 different behaviour patterns clustered in seven behavioural categories provides an initial framework for understanding the behavioural repertoires of Indian pangolins. Further studies on behavioural biology of Indian pangolins are urgently required for facilitation of both ex-situ and in-situ conservation of the species. Since a comprehensive knowledge on behavioural biology of the Indian pangolin is essential for its management in captivity, descriptions of this paper may also useful in improving the husbandry and management of captive Indian pangolin and design future conservation efforts.

\section{Conflict of Interests}

The authors declare that none of them have a conflict of interests.

\section{Acknowledgments}

The authors are thankful to Central Zoo Authority (CZA), New Delhi for the financial support and the permission to undertake the research in the Indian pangolins at Pangolin Conservation Breeding Center, Nandankanan Zoological Park, Odisha. We are thankful to Dr. L. N. Acharjyo, former veterinary officer, NKZP, Odisha for going through the manuscript and for his valuable suggestions.

\section{References}

[1] R. I. Pocock, "The external characteristics of the pangolins (Manidae)," Proceedings of Zoological Society of London, vol. 94, pp. 707-723, 1924.

[2] M. E. Heath, "Manis crassicaudata," Mammalian Species, vol. 513, pp. 1-4, 1995.

[3] S. Israel, T. Sinclair, B. Grewal, and H. J. Hoefer, Indian Wildlife, APA Productions, Hong Kong, 1987.

[4] S. H. Prater, The Book of Indian Animals, Bombay Natural History Society/Oxford University Press, New Delhi, India, 3rd edition, 2005. 
[5] T. J. Roberts and J. Vielliard, "Commentaires sur le grand pangolin indien Manis crassicaudata," Mammalia, vol. 35, pp. 610-613, 1971.

[6] S. Mishra and S. Panda, "Distribution of Indian pangolin Manis crassicaudata Gray (Pholidota, Manidae) in Orissa: a rescue prospective," Small Mammal Mail, vol. 3, no. 2, pp. 51-53, 2012.

[7] D. Challender, "Asian Pangolins: how behavioural research can contribute to their conservation," in Proceedings of the Workshop on Trade and Conservation of Pangolins Native to South and Southeast Asia, S. Pantel and S. Y. Chin, Eds., pp. 95-102, TRAFFIC Southeast Asia, Selangor, Malaysia, 2009.

[8] L. N. Acharjyo, "Management of Indian pangolin in captivity," in Souvenir, 125 years of Calcutta zoo (1875-2000), pp. 27-30, Zoological Garden, Alipore, Calcutta, India, 2000.

[9] R. K. Mohapatra and S. Panda, "Behavioural sampling techniques and activity pattern of Indian pangolins Manis crassicaudata (Mammalia: Manidae) in captivity," Journal of Threatened Taxa, vol. 5, no. 17, pp. 5247-5255, 2013.

[10] R. K. Mohapatra and S. Panda, "Husbandry, behaviour and conservation breeding of Indian pangolin," Folia Zoologica, vol. 63, no. 2, pp. 73-80, 2014.

[11] S. Mishra and S. Panda, "Nocturnal behaviour of Indian pangolin (Manis crassicaudata) in captivity," Indian Zoo Year Book, vol. 6, pp. 128-136, 2010.

[12] T. W. Clark, L. Richardson, S. C. Forrest, D. E. Casey, and T. M. Campbell, "Descriptive ethology and activity pattern of black footed ferret," Great Basin Naturalist Memoirs, vol. 8, pp. 115$134,1986$.

[13] V. Menon, Indian Mammals: A Field Guide, pp. 330-353, Hachette Book Publishing India, Gurgaon, India, 2014.

[14] L. N. Acharjyo and R. Misra, "Birth of Indian pangolin (Manis crassicaudata) in captivity," Journal of the Bombay Natural History Society, vol. 69, no. 1, pp. 174-175, 1972.

[15] W. W. A. Phillips, "A note on the habits of the Indian pangolin (Manis crassicaudata)," Spolia Zeylanica, vol. 14, p. 333, 1928.

[16] G. J. Mason, “Stereotypies: a critical review," Animal Behaviour, vol. 41, no. 6, pp. 1015-1037, 1991.

[17] R. H. Petters, The Ecological Implication of Body Size, Cambridge University Press, Cambridge, Mass, USA, 1983.

[18] T. L. Schmidt, "Ethogram of the giant anteater (Myrmecophaga tridactyla) in captivity: an experience in the Temaikèn Foundation," Edentata, vol. 13, pp. 38-49, 2012.

[19] D. W. S. Challender, N. V. Thai, M. Jones, and L. May, “Timebudgets and activity patterns of captive Sunda pangolins (Manis javanica)," Zoo Biology, vol. 31, no. 2, pp. 206-218, 2012.

[20] M. E. Heath, "Manis temminckii," Mammalian Species, vol. 415, pp. 1-5, 1992.

[21] M. E. Heath, “Manis pentadactyla," Mammalian Species, vol. 414, pp. 1-6, 1992.

[22] N. V. Thai, L. Clark, and T. Q. Phuong, Management Guidelines for Sunda pangolin (Manis javanica), Carnivore and Pangolin Conservation Program, 2010.

[23] J. V. Watters, S. W. Margulis, and S. Atsalis, "Behavioral monitoring in zoos and aquariums: a tool for guiding husbandry and directing research," Zoo Biology, vol. 28, no. 1, pp. 35-48, 2009.

[24] C. A. ven Ee, "A note on breeding the Cape pangolin Manis temminckii at Bloemfontein zoo," International Zoo Year Book, vol. 6, pp. 163-164, 1966.

[25] N. H. G. Jacobson, R. E. Newbery, M. H. Dewet, P. C. Viljoen, and E. Pieterson, "A contribution to the ecology of the steppe pangolin Manis temminckii in the transvaal," Zeitschrift für Säugetierkunde, vol. 56, pp. 94-100, 1991.

[26] R. K. Mohapatra, S. Panda, and M. V. Nair, "Architecture and microclimate of burrow systems of Indian pangolins in captivity," in Indian Zoo Year Book, vol. 8, pp. 12-24, 2014.

[27] F. Bao, S. Wu, C. Su, L. Yang, F. Zhang, and G. Ma, "Air temperature changes in a burrow of Chinese pangolin, Manis pentadactyla, in Winter," Folia Zoologica, vol. 62, no. 1, pp. 4247, 2013. 

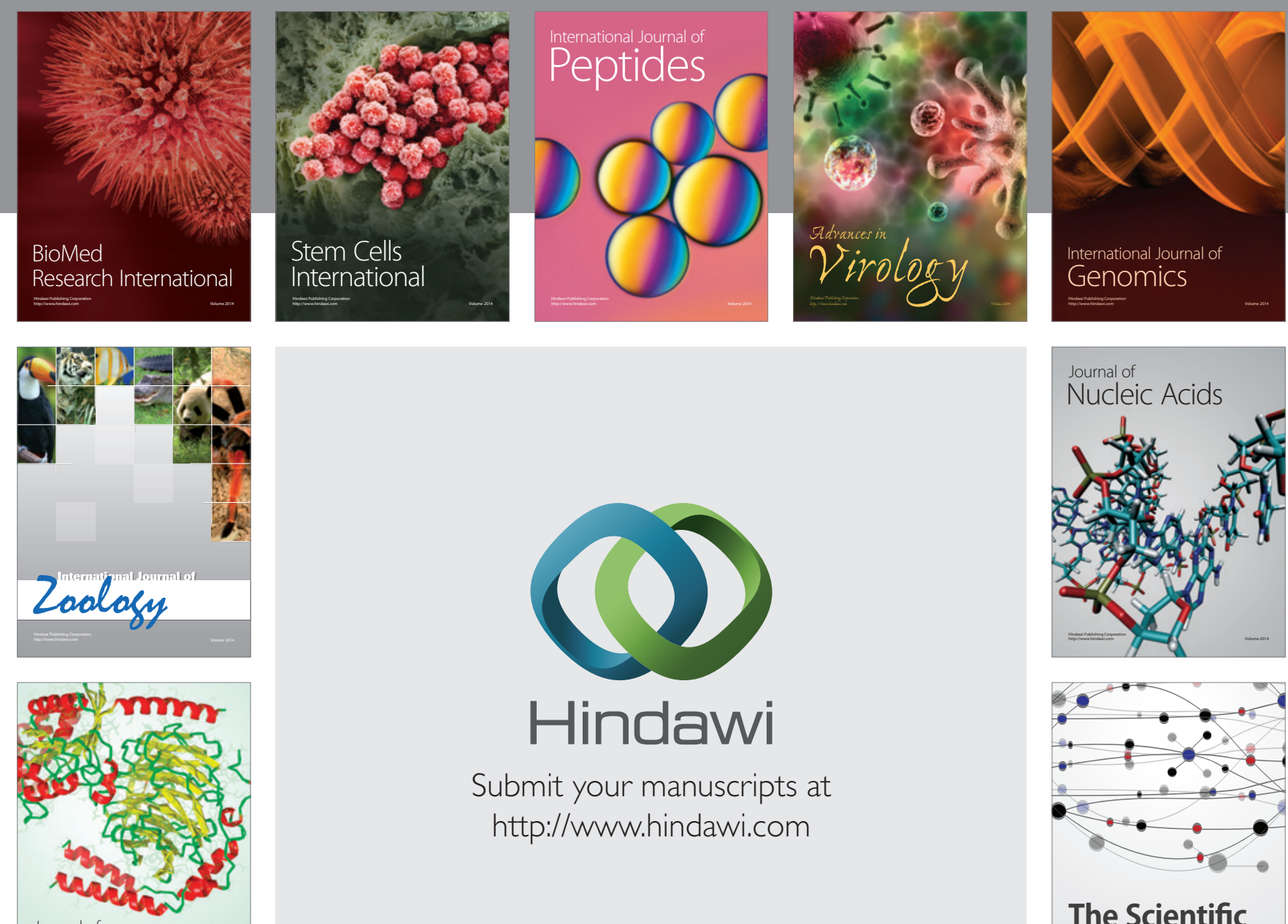

Submit your manuscripts at

http://www.hindawi.com

Journal of
Signal Transduction
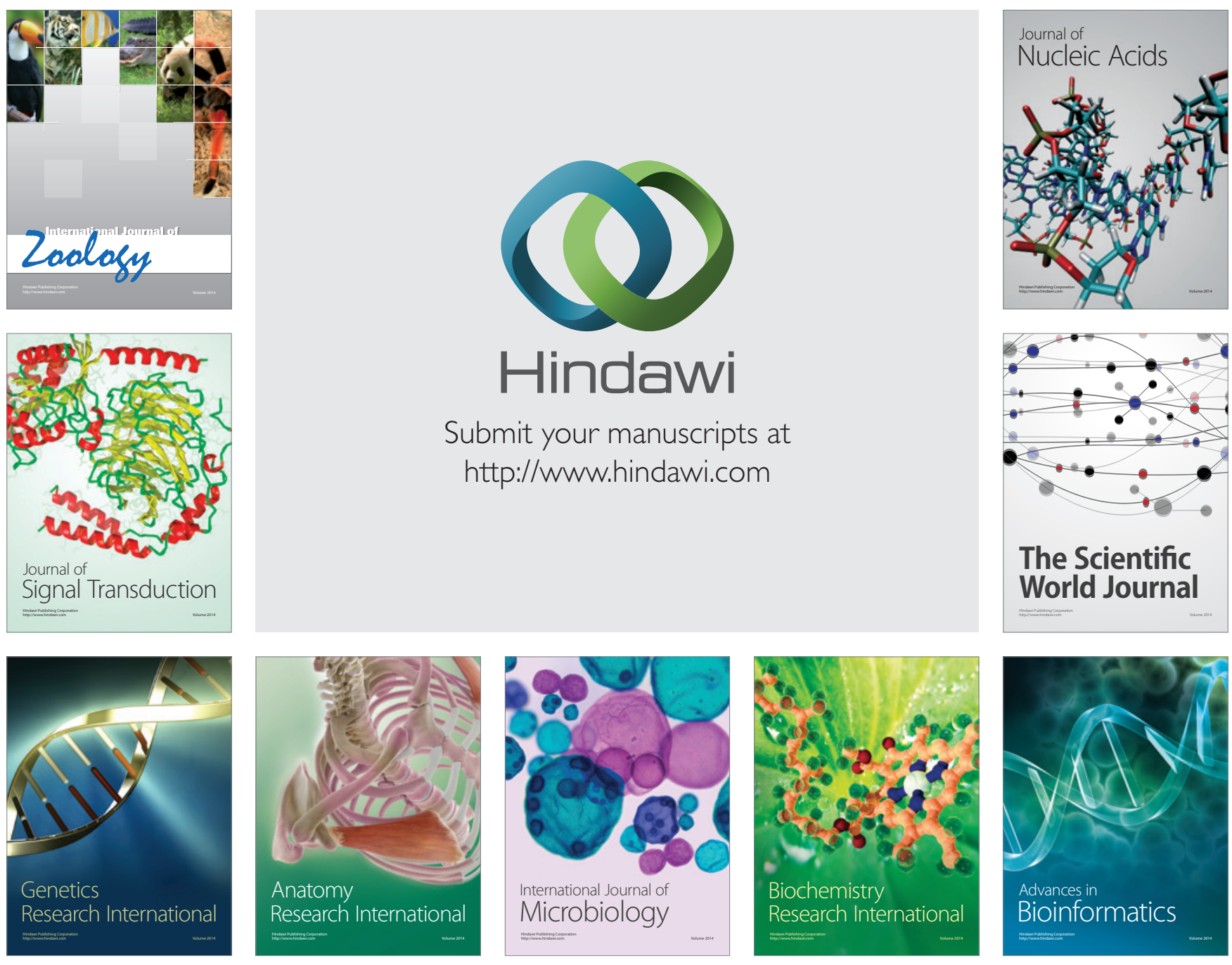

The Scientific World Journal
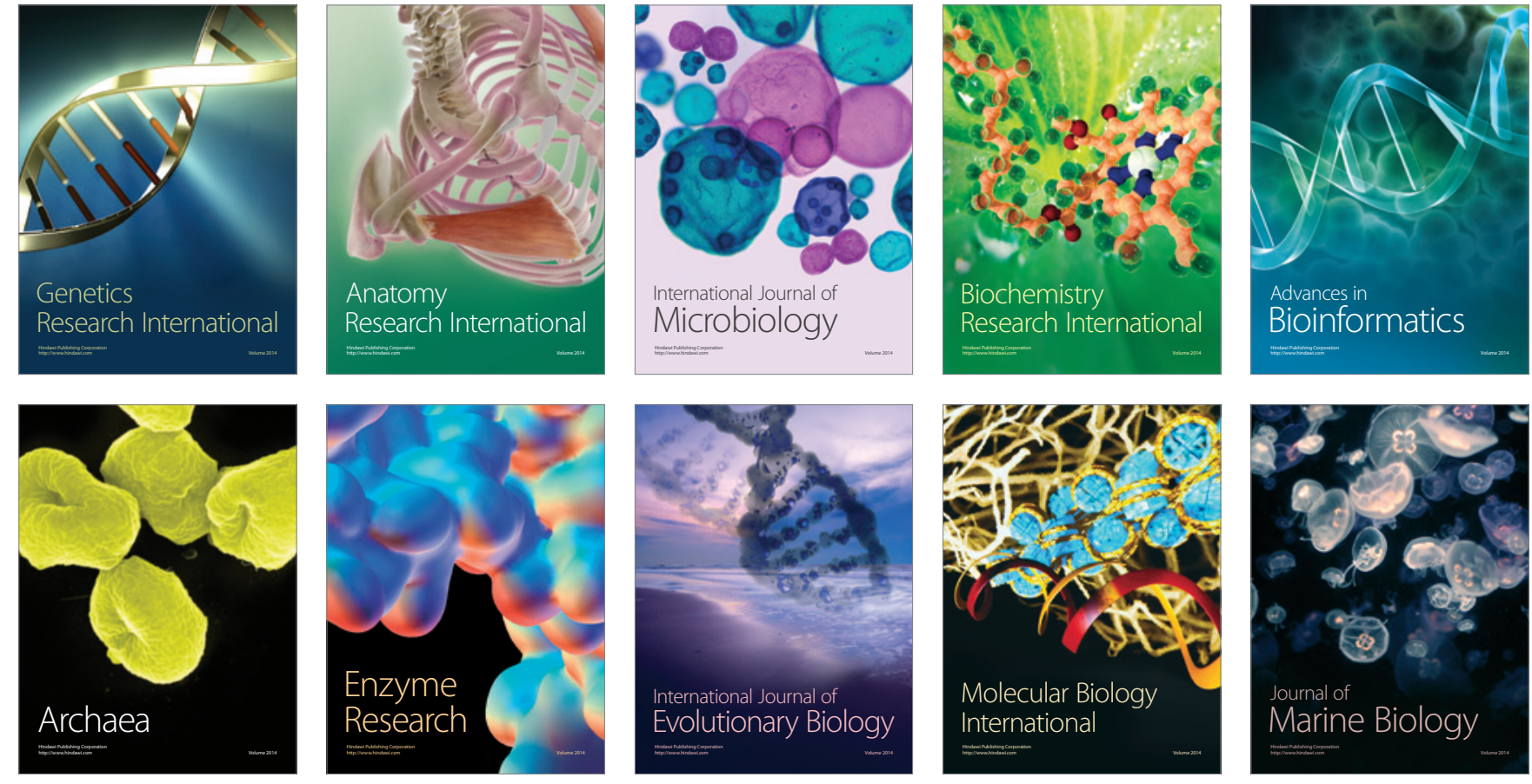